\title{
Les farces dans Gaspard des Montagnes d'Henri Pourrat
}

Jacques Chocheyras

\section{Q OpenEdition}

\section{Journals}

Édition électronique

URL : http://journals.openedition.org/recherchestravaux/277

DOI : 10.4000/recherchestravaux.277

ISSN : 1969-6434

Éditeur

UGA Éditions/Université Grenoble Alpes

\section{Édition imprimée}

Date de publication : 30 mai 2005

Pagination : 161-165

ISBN : 0151-1874

ISSN : 0151-1874

\section{Référence électronique}

Jacques Chocheyras, «Les farces dans Gaspard des Montagnes d'Henri Pourrat », Recherches \& Travaux [En ligne], 67 | 2005, mis en ligne le 30 septembre 2008, consulté le 08 septembre 2020. URL: http://journals.openedition.org/recherchestravaux/277 ; DOI : https://doi.org/10.4000/ recherchestravaux.277 
Jacques CHOCHEYRAS

Université Stendhal - Grenoble 3

\section{Les farces dans Gaspard des Montagnes d'Henri Pourrat}

Composée entre I9I8 et 1931, la grande fresque romanesque d'Henri Pourrat a pour titre complet Les vaillances, farces et aventures de Gaspard des Montagnes. Ce titre regroupe quatre tomes, publiés chez Albin Michel de I922 à I93I, intitulés respectivement: Le Château des sept portes, ou les enfances de Gaspard (1922), L'Auberge de la belle bergère ou Quand Gaspard de guerre revint (I925), Le Pavillon des amourettes ou Gaspard et les bourgeois d'Ambert (1930), La Tour du Levant ou Quand Gaspard mit fin à l'histoire (193I). À la fois roman paysan avec pour cadre précis les monts et la plaine du Livradois (entre le Forez et la Limagne), roman d'aventures (histoire de la contre-lettre qui constitue le fil directeur du récit), roman historique (l'action se déroule entre I809 et I820 environ), roman noir (avec brigands, assassinats, tentatives de viols, empoisonnements, batailles rangées), roman d'amour rousseauiste ("Anne-Marie vient au verger» rappelle la promenade de Julie et de Saint-Preux sur le lac), roman social enfin, Gaspard des Montagnes est un monde foisonnant dont le héros est une sorte de chevalier sans peur et sans reproche dont l'énergie et celle de ses compagnons n'excluent pas la truculence. En même temps, Henri Pourrat, au lendemain de la Première Guerre mondiale qui vit l'effondrement d'une civilisation paysanne, a voulu faire de cette épopée un conservatoire de toutes les coutumes, histoires (chaque tome est divisé en sept "veillées» divisées chacune en six "pauses») et modes de vie locaux de ce petit coin d'Auvergne (la limite entre le francoprovençal, à l'est, et l'occitan auvergnat à l'ouest, qui court le long de la ligne de crête des monts du Forez, sépare le département de la Loire de celui du Puy-de-Dôme et marque encore aujourd'hui le passage de la région Rhône-Alpes à la région Centre). Henri Pourrat a toujours vécu à Ambert, dans la «capitale» du Livradois, ce minuscule terroir isolé en plein cœur de la France et a recueilli tout au long de sa vie les matériaux de ses livres, à commencer par Gaspard, comme il ramenait de 
ses longues promenades champignons, châtaignes ou "perons» (petites poires sauvages). Il a aussi bien connu les «bourgeois» d'Ambert.

Tout cela explique que les farces («bons tours joués à quelqu'un" disent à peu près les dictionnaires) jouent un grand rôle dans le roman, comme il est d'ailleurs annoncé dans son titre. Tout au moins dans les trois premiers tomes; le dernier, sauf erreur, n'en comporte pas. Tantôt elles sont racontées (c'est le cas le plus rare) directement par le porte-parole de l'auteur, à savoir "la vieille», tantôt attribuées (c'est le plus grand nombre) à Gaspard dont l'esprit imaginatif, la malice, l'ingéniosité et la demi-culture associés font à chaque fois merveille, tantôt mises au crédit de ses acolytes qui rivalisent avec lui aux dépens de leurs victimes. Celles-ci sont de deux sortes: il y a ceux (ou celles) dont on se moque et ceux (ou celles) dont on se venge. Et le ton, on s'en doute, n'est pas tout à fait le même dans un cas et dans l'autre.

À la première catégorie appartiennent «le Barthaud", vieux maitre d'école aussi naïf qu'ignorant aux frais duquel on se divertit gentiment, mais surtout une veuve, Dorothée, dite la Poule-Courte, dont les commérages, à mainte reprise, font du tort ou risquent de nuire à la protégée de Gaspard, sa cousine, la belle et sage Anne-Marie, mariée malgré elle à un des «bourgeois» du Velay (des "étrangers» donc) d'autant plus haïs qu'ils sont des voisins), monstre froid animé par un désir de vengeance contre elle et sa famille. De ces "messieurs» inquiétants qui ont partie liée avec la canaille, on tirera vengeance par le feu et par le sang. Mais des «bourgeois» d'Ambert plus filous que méchants: M. César, son frère "tonton Amédée» et leur sœur, la belle et intrigante Elvire, on se débarrassera par le ridicule qui finira bel et bien par tuer (involontairement et pas du fait de Gaspard) M. César, dit «l'Empereur».

Mais ce qui fait le charme de ces historiettes, c'est qu'Henri Pourrat est un merveilleux conteur (il a d'ailleurs réuni en dix de ses volumes Le Trésor des contes sans compter, sous d'autres titres, six autres volumes de contes) avec toute la verve et la langue savoureuse des auteurs du Moyen Âge et de la Renaissance (la grivoiserie en moins). C'est d'ailleurs un véritable fabliau que «L'histoire du curé trop friand qui fut guéri de sa paralysie par les voleurs de moutons» (deuxième veillée, quatrième pause):

Ha! pauvre monsieur le curé! Les diables sont dans le cimetière qui croquent les os des morts! [...] les entendez-vous?» Diantre, M. le curé commençait de croire que tous les diables étaient là qui fracassaient les os des morts dans leurs mandibules $[\ldots]$

Dans le registre comique, Gaspard entre en scène avec l'histoire du sufficit (cinquième veillée, deuxième pause). Comme il s'est frotté de latin au collège d'Arlanc, et qu'il a acquis une réputation de savant, il profite de celle-ci pour 
se gausser en cachette de son ancien "magister» (maitre d'école), Barthélemy, dit le Barthaut.

Gaspard arrivé, tout courant aussi, le magister lui déduit la chose sur le coudert même, le regardant avec les yeux qu'on fait à un homme qui tient votre salut dans sa manche-Quoi, c'est là que le bât vous blesse? C'est pour ça que vous me faites venir si grand train de chez moi où j’ai laissé les pois au lard sur la table? Un sufficit? Hé! c'est une queue d'âne, ne m'en tarabustez plus la cervelle.

Entre Monseigneur (l'évêque de Clermont en tournée pastorale) et Dorothée la Poule-Courte, il va y avoir beau jeu.

Continu sur sa lancée du sufficit, Henri Pourrat emprunte la voix de Jeuselou, qui est un peu le poète du groupe pour dire «le conte du curé au langage trop fin ", autre fabliau dont le personnage principal est encore un curé, victime cette fois de son invention langagière:

Tâche de te mettre ces noms dans la tête, dit le curé, et ne te sers jamais des autres, qui sentent leur rustique» [...] Et le curé se rôtit tout à son aise, pour avoir voulu que son domestique parlât autrement que les bons chrétiens.

Mais c'est pour revenir bientôt aux manigances de la Poule-Courte qui lui valurent de Gaspard et de ses compères de devenir la dinde de la «farce du panier» (cinquième pause) :

Gaspard rêva une minute. Le bon curé lui vit un tel air de diablerie qu'il s'écria:

- À moins, chenapan, si c'est une farce, qu'elle ne soit pas trop carabinée!

- Moi, des farces?... Ah! pauvre monsieur le curé! Mais je vous aurais bien de l'obligation si vous me prêtiez le grand panier que je vois sous votre hangar.

C'était une sorte de corbeille où l'on mettait les noix à l'arrière-saison.

Gaspard, avec l'aide de deux séides va faire de cette corbeille l'instrument d'une leçon particulièrement réjouissante, pour lui apprendre que les poules se couchent tôt.

Mais la farce devient "hénaurme», comme aurait dit Flaubert, avec l'histoire de la Poule-Courte qui faillit périr en répandant ses entrailles (sixième pause):

Gaspard eut la charité de prendre un grand seau d'eau froide et de le lui envoyer en gerbe dans le nez. Le remède la remit à peine. Ses commères eurent à l'emporter et à la coucher fumante de peur.

À partir de là (nous sommes à peine au cinquième du roman) l'univers s'assombrit, le ton change. Nous sommes en I8I4 et c'est «la grande levée». Gaspard et ses amis partent pour se battre et participer à la campagne d'Allemagne (Lützen, Bautzen) et de France. Pendant ce temps, Anne-Marie est mariée à l'inquiétant $\mathrm{M}$. Robert et seul, Jeuselou, qui n'était pas apte au service, entretient l'esprit du groupe de joyeux drilles desquels il a fait partie. 
"Les bavardages de la Poule-Courte» arrivent à ce résultat que, cette fois, son ânichon est changé en "âne sauvage»! c'est-à-dire zèbre, on devine par quel procédé (L'Auberge de la belle bergère, troisième veillée, quatrième pause). Mais "quand Gaspard de guerre revint ", il est comme "endiablé» à tel point qu'il apprend à parler à la chienne du curé de Besse (sixième veillée, première pause), la présence d'un curé comme personnage principal est presque, à coup sûr, le signe que nous avons à faire à un fabliau :

Des progrès? Ha, que trop! À peine savait-elle parler qu'elle commençait de dégoiser des horreurs [...] À l'entendre, pauvre monsieur le curé, vous étiez porté sur la bouche, vous mettiez trois gros quarts d'heure pour manger une grive [...].

Même atmosphère quand Gaspard repêche un fantôme coiffé d'un pot, résultat de «la promenade du magister et du tailleur» (quatrième pause) qui se poursuit avec «la soupe à la soldate» (cinquième pause) que Gaspard a le secret de faire avec un pavé... «La nuit fut bonne. Il n’y avait pas beaucoup de puces dans cette auberge: les punaises les avaient toutes mangées.»

Par la suite, à part la farce du Mardi gras, le climat s'alourdit encore avec $L e$ Pavillon des Amourettes ou Gaspard et les bourgeois d'Ambert, où c'est la guerre ouverte (faisant pendant à la Terreur blanche) entre les anciens soldats de l'Empire et les notables réactionnaires de la Restauration. Mais paradoxalement, c'est là que les farces de Gaspard et de ses pairs (dont ses deux frères, le Dragon et Benoni Corps-de-Bœuf, et le géant Plampougnis, précurseur d'Obélix) sont les plus nombreuses, comme si elles avaient pour rôle d'apaiser la tension née des situations angoissantes. Les victimes n'en sont plus des simples, comme la Poule-Courte, mais des avoués, ou percepteurs madrés, retors, parfois véreux, et le ton se fait grinçant, le rire vengeur. Tout se passe non plus dans des villages, mais à la ville (Ambert, revisitée plus tard par Jules Romain dans Les Copains) et l'on songe à la description de la petite ville dans Les Caractères de la Bruyère.

Les luttes les plus âpres ont lieu, en période de disette, entre les paysans, représentés et défendus par Gaspard et ses amis, et les accapareurs de blé, en la personne de M. César. Elles occupent tout l'espace des quatrième et cinquième pauses de la sixième veillée. Avec "Le drap de M. César» «Le marché du dimanche» et "La maison Chargnat», elles prennent le chemin de crises révolutionnaires ("Troubles sur le Poutel»), que les provocations audacieuses du héros paysan contribuent à la fois à dédramatiser et à résoudre («Les portes de la maison Chargnat disparaissent - L'événement»). Le drame est évité de justesse et le rire sort finalement vainqueur de l'épreuve de force contre César Chargnat. 
À partir de là (troisième veillée), il est relayé comme «bête noire» par «la tête de Turc", son frère Amédée, le percepteur, vieux garçon pique-assiette, un peu escroc, qui ne déteste pas de s'encanailler avec le peuple: «M. Amédée manque de perdre la vue. La tête de veau mugissante» (cinquième veillée, troisième pause), dont les titres disent bien de quels tours pendables il peut être l'objet, sans pour autant que les victimes traditionnelles de la bonne humeur féroce des gais lurons soient abandonnées: «La Poule-Courte assassinée. Elle sauve le tailleur de la rage» (quatrième veillée, première pause); "Gaspard et le dîner du curé de Marsac - L'ânichon de la Poule-Courte s'envole».

M. César lui, va finir victime d'une farce. Il manque d'abord de devenir enragé: «M. César perd sa botte - Il la retrouve et ne l'a pas davantage» (quatrième veillée, cinquième pause) et devenu, une proie facile à cause de sa cupidité auprès de ses concitoyens, il meurt d'apoplexie en voulant recueillir à son compte le "dernier bien du Guillaume» (quatrième veillée, sixième pause). "Ces choses se sont racontées longtemps. Puis, de veillées en veillées, comme la montagne se mêle aux nuages, elles se sont fondues et mêlées à d'autres contes.»

«L'histoire» n'est pas finie, et le récit se fait de plus en plus prenant dans le dernier tome de Gaspard. Mais le conte n'y a plus part, et le rire non plus, par conséquent. Il laisse la place à l'émotion et à l'assouvissement des passions.

J'ai essayé d'évoquer sans le déflorer, l'aspect ludique de cette somme unique. Mais si Gaspard vous était conté par le menu, je suis sûr que vous y prendriez comme moi un plaisir extrême. C'est la grâce que je te souhaite, mon cher Serroy. 